\title{
CONSTITUCIONALIZAÇÃO DO DIREITO CIVIL E DIREITOS FUNDAMENTAIS: UMA ABORDAGEM CRÍTICA
}

\author{
CONSTITUTIONALIZATION OF CIVIL LAW AND FUNDAMENTAL RIGHTS: A \\ CRITICAL APPROACH
}

Fabio Queiroz Pereira

Santiago Pinto

\begin{abstract}
SUMÁRIO: Introdução: o conteúdo humano e o direito civil - 1. A relação entre direitos fundamentais e o direito civil - 2. A constitucionalização do direito civil - 3. Por uma abordagem crítica da constitucionalização do direito civil - Conclusões - Referências Bibliográficas
\end{abstract}

RESUMO: A crítica desenvolvida visa a chamar atenção para os desvios ocorridos em razão da chamada constitucionalização do direito civil. Para isso, analisa a evolução do papel dos direitos fundamentais e sua relação com o direito civil, bem como as principais linhas que definem o referido processo de constitucionalização. Assim, por meio de uma abordagem crítica, aponta caminhos à efetivação de um diálogo leal e verdadeiro entre Constituição e direito privado.

Palavras chave: Direitos. Fundamentais. Constitucionalização. Civil. Crítica.

ABSTRACT: The present critique aim to call attention to the misleadings caused by the so called constitutionalization of civil law by analysing the evolution of fundamental right's role, their relation with civil law as well as the main characteristics of the constitutionalization process. The article offers therefore perspectives in order to effectuate a loyal and real dialogue between the Constitution and Private Law.

Keywords: Rights. Fundamental. Constitutionalization. Civil. Critical.

\section{INTRODUÇÃO: O CONTEÚDO HUMANO E O DIREITO CIVIL}

A ideia de um sistema de direito fundado em uma lógica essencialmente patrimonialista cede espaço, presentemente, para a ponderação de valores humanos na criação e na aplicação das normas jurídicas.

A dignidade da pessoa humana é, hoje, pedra basilar sob a qual se sustenta o ordenamento jurídico. Por meio da adequada ponderação e aplicação desse princípio, faz-se possível a concretização de realidades que atentem para o fato de que o homem deve ser considerado como fim em si mesmo. Nesse sentido, são as palavras de SIQUEIRA JÚNIOR (2008: p. 273):

A dignidade da pessoa humana é o atributo moral do indivíduo, que o qualifica enquanto ser. A consequiência imediata desse pressuposto é que o homem é dotado de valor próprio, não podendo ser transformado em objeto. O valor absoluto dignidade da pessoa humana informa todo o sistema jurídico. O homem enquanto ser é sagrado, sendo o valor fonte de todos os direitos.

No Brasil, em particular, com o advento da Constituição da República de 1988, pode-se constatar uma preocupação premente com as situações jurídicas subjetivas, individuais e coletivas, que impulsiona, constantemente, a releitura de diversos institutos jurídicos. O aludido fato se explica, sobretudo, em razão da inserção da 
dignidade da pessoa humana no rol dos fundamentos da República, conforme prenuncia $\mathrm{o}$ art. $1^{\circ}$ do texto constitucional.

Diante de tal panorama, os estudos de direito civil brasileiro têm sido realizados, de forma constante, tomando por intróito embasamento a ideia de eficácia constitucional nas relações privadas, de modo que o assim denominado processo de constitucionalização do direito privado transformou-se no núcleo do qual são extraídos e reinterpretados conceitos e institutos.

Entre nós, o interesse pela referida linha doutrinária surgiu, principalmente, durante o período final de vigência do Código Civil de 1916. Diante de um texto de caráter individualista, que não expressava os anseios sociais por uma visão humana do direito, a doutrina ensaiou buscar fundamentos para tanto no novel texto constitucional, de forma a tentar dar contornos adequados ao que se esperava do direito civil brasileiro.

Como implicação de tal movimento, a eficácia dos direitos fundamentais passa a ser sopesada em uma nova perspectiva, chegando-se, até mesmo, a juízos pautados na desnecessidade de intermediação da legislação ordinária. Em paralelo, pode-se perceber que são transplantados à esfera privada, sem quaisquer regulações, certos mandamentos constitucionais, redesenhando-se, como se veio de dizer, conceitos e institutos e criando-se, assim, uma nova perspectiva de estudos doutrinários e aplicações jurisprudenciais.

Nesse contexto, demonstra-se extremamente relevante a adoção, pelo intérprete, de uma postura analítica no intuito de melhor compreender tais fenômenos, de possibilitar um diálogo adequado entre os mandamentos constitucionais e o direito civil e de contribuir para a construção de novos rumos à compreensão e ao desenvolvimento do direito civil.

\section{A relação entre direitos fundamentais e o direito civil}

A empreitada, aqui, exige estrito cumprimento de limitações metodológicas, bem como o propósito de servir como alerta demanda simplicidade, porém agudeza.

A temática dos direitos fundamentais encontra-se amplamente desenvolvida por vasta literatura, sendo o espaço jurídico brasileiro especialmente receptivo e fecundo no que lhe diz respeito.

Protegê-los significa "criar e manter os pressupostos elementares de uma vida na liberdade e na dignidade humana" (HESSE, 1986 apud BONAVIDES, 1997: p. 514). Tudo aquilo que se revele essencial à realização plena do indivíduo, portanto, deve ser reconhecido e efetivado.

Tais direitos, como regra, são percebidos por meio de normas de caráter constitucional e, por isso, detêm um elevado status jurídico, estando no topo da estrutura hierárquica do ordenamento.

Polêmica, porém, subsiste com relação ao debate acerca da relação dos direitos fundamentais com o direito privado, uma vez que o caminho percorrido por tal contenda, podendo ter chegado a um consenso como o relativo à efetividade dos direitos fundamentais e à força normativa das normas que os prevêem (ideias, hoje, aceitas com naturalidade), acabou por não o fazer.

Por isso, para efeito de imediata apreensão, para se visualizar os eventuais desvios incorridos, alguma análise desse caminho deve ser intentada.

Segundo CANARIS, partindo-se da distinção entre as funções dos direitos fundamentais como proibições de intervenção (proibições de excesso) e imperativos de tutela (proibições de insuficiência), tem-se que as leis de direito privado, quando trazem eventualmente intervenções ilegítimas em direitos fundamentais, devem ser controladas 
à luz da função de proibição de excesso. Além disso, como garantia de proteção e defesa dos direitos fundamentais, as leis de direito privado devem ser percebidas como instrumentos à concretização da função de imperativo de tutela, é dizer, como instrumentos à efetivação dos direitos fundamentais. Pode mesmo ocorrer que ambas as funções se realizem simultaneamente, hipótese na qual há,

(...) por um lado, indagar se a intervenção nos direitos fundamentais de uma parte onera esta de forma que ofenda a 'proibição do excesso'; e, por outro lado, averiguar se a lei fica, por exemplo, aquém daquele mínimo que a Constituição impõe para protecção da outra parte (CANARIS, 2003: p. 34).

A exigência de intermediação pelo direito ordinário se mostra clara, seja para o seu próprio controle, por meio da verificação da constitucionalidade e da proporcionalidade de suas normas, seja para a operacionalização dos comandos e valores constitucionais que lhe devem guiar.

Como pretende o autor, "fica aqui, em regra, aberto ao legislador um amplo espaço de livre conformação" (CANARIS, 2003: p. 66). Amplo, porém não ilimitado: o legislador democrático deve atenção às opções políticas e axiológicas de caráter constitucional. Os direitos fundamentais, portanto, funcionam também como limite à sua atuação: limite a intervenções ilegítimas.

Em razão de sua força normativa, os direitos fundamentais, de embasamento ao exercício de liberdades negativas contra o Estado, passam a ser reconhecidos como princípios orientadores do comportamento de todos os sujeitos. É dizer, sua efetivação e a construção de um dever de proteção de tais direitos devem ter em conta, também, eventuais ameaças resultantes da atuação de particulares, de relações eminentemente privadas. A distinção entre público e privado esfacela-se, para tanto, como critério de relevância. Contudo, parece evidente que toda essa atividade deve se sujeitar, como já se disse, ao controle de constitucionalidade e de proporcionalidade, até porque são proscritas intervenções que se mostrem ilegítimas, o que difere do automático repúdio a qualquer ingerência.

Some-se a isso o fato de que, em razão da necessidade de obediência ao próprio ordenamento constitucional, não se é dado ignorar, pura e simplesmente, a existência legítima de legislação ordinária. Por isso, em sendo possível, é de se concluir que a efetivação dos direitos fundamentais deve se dar pelo direito privado.

Veja-se MOTA PINTO (2006: p. 368):

Julgamos que a aplicação, à actividade de entidades privadas, das normas que consagram direitos fundamentais deve ocorrer, em primeira linha, através de normas de direito privado, quer estas se limitem a reproduzir o teor das normas constitucionais, quer contenham conceitos indeterminados ou cláusulas gerais, a preencher e concretizar segundo os valores constitucionalmente consagrados, e, em particular, numa actividade de 'interpretação conforme aos direitos fundamentais' (Grifos no original).

Nesse mesmo sentido, encontra-se a proposta de MARTINS-COSTA sobre o papel do Código Civil brasileiro como estrutura receptora dos direitos fundamentais e como possibilidade técnica de sua concretização e expansão no direito privado (MARTINS-COSTA, 2006: p. 64-65). A autora, inclusive, já havia, em outra oportunidade, se pronunciado no sentido de que as cláusulas gerais são as responsáveis 
pelo necessário diálogo entre valores e conceitos presentes no Código Civil, na Constituição e nos demais diplomas normativos. (MARTINS-COSTA, 1998: passim).

Trata-se, como se pode ver, de verdadeiro exercício dialético a ser realizado. Entretanto, enquanto exercício dialético, exige a participação tanto do Código Civil, quanto da Constituição. É dizer, ignorar a existência legítima de regulamentação infraconstitucional, seja ela de caráter público ou privado, à guisa de suposta defesa e aplicação de valores constitucionais, pode acabar por macular os frutos pretendidos, por ser, não raras vezes, disfarce à arbitrariedade.

Não se trata, absolutamente, de retorno a alguma ideia de que os direitos fundamentais somente tenham relevância indireta ou mediata, a depender de expressa regulamentação legislativa para serem efetivados. Estando no centro do ordenamento jurídico, sua não efetivação demonstra grave falha no sistema jurídico e, pior, no pensamento jurídico. Defender, porém, que essa efetivação se dê por meio do direito privado não implica automaticamente um absurdo que tal.

Situações reguladas positivamente por lei manter-se-ão por ela regidas, uma vez que sobreviva tal regulamentação ordinária ao controle de constitucionalidade e de proporcionalidade de suas disposições. É dizer, estando conforme com a Constituição.

Aliás, mesmo na eventual hipótese de ausência de regulamentação legal específica, o direito privado sustentar-se-á apto à efetivação dos direitos fundamentais, seja por meio das chamadas cláusulas gerais, pelo preenchimento dos conceitos abertos, ou ainda pelos princípios gerais de um ordenamento jurídico. Nesse sentido, discorre VIEIRA DE ANDRADE (1987: p.291):

Deve [o juiz], se for o caso disso, recorrer aos conceitos abertos próprios do direito privado e preenchê-los com a ajuda dos valores constitucionais (...). Se tal se revelar insuficiente, deverá o juiz decidir o caso a partir dos princípios gerais, aplicando o princípio da harmonização, sempre que se possa afirmar que há um valor ou interesse constitucionalmente relevante que se contrapõe à eficácia normativa absoluta do preceito constitucional (normalmente, a autonomia privada).

Dessa passagem, em especial, merece destaque a afirmação da necessidade de harmonizar a pretensão de absolutismo na aplicação dos preceitos constitucionais com valores e interesses igualmente relevantes - constitucionalmente relevantes -, como a autonomia privada.

O direito privado traz consigo princípios fundantes para as sociedades ocidentais. Não cabe, aqui, ensaiar sequer a menor reconstrução de sua trajetória. Contudo, parece evidente a insustentabilidade de qualquer teoria que parta da premissa de que é ele o responsável pelas mazelas de toda uma forma de organização social. Tanto pior quando tente corrigi-las a partir da adoção de uma postura arbitrária e antidemocrática de desprezo à legislação infraconstitucional.

Veja-se que CANARIS, ao falar das intervenções ilícitas em direitos fundamentais, no contexto alemão, assevera que, contra elas, a função de imperativo de tutela se dá "através dos chamados deveres no tráfico" e que, por isso,

O desenvolvimento destes deveres no tráfico recebe assim, por intermédio da função dos direitos fundamentais como imperativos de tutela, extraída dos artigos 2.. , n. $^{\circ} 2$ e 14, ambos da LF, uma legitimação jurídico-constitucional, sendo certo, porém, que esta lhes não é indispensável, já que, contrariamente a críticas insistentes, os 
deveres no tráfico estão $\log$ - e sempre estiveram, desde o início suficientemente legitimados no plano do direito civil (CANARIS, 2003: p. 110).

A tarefa básica do intérprete, visando à máxima efetivação dos comandos constitucionais, deve inarredavelmente resultar no aproveitamento das regulamentações legislativas que se mostrem aptas à real e eficaz concretização de tais direitos, para além de discursos meramente teóricos ou retóricos. Por isso que, quando não aproveitáveis, quando frontalmente contrários ao sentido normativo dos mandamentos constitucionais, os dispositivos das legislações ordinárias devem simplesmente sucumbir ao exame de constitucionalidade e de proporcionalidade.

\title{
2. A constitucionalização do direito civil
}

Adentrando o tema específico da constitucionalização do direito civil, verifica-se que o aludido fenômeno é evidenciado, principalmente, em uma hermenêutica que tenha seu núcleo na Constituição e em uma suposta identificação da sua eficácia direta no âmbito das relações privadas. Trata-se de desenvolvimento teórico que tem origem no ordenamento jurídico italiano, mas que obteve grande receptividade em doutrina e estudos brasileiros.

Partindo do pressuposto de que os institutos de direito civil carregam em si os conteúdos voluntarista e individualista, típicos do estado liberal ${ }^{\mathrm{i}}$, a escola do direito civil constitucional intenta, à sua maneira, dar novos contornos ao ordenamento jurídico privatístico, a partir da valoração do conteúdo normativo da Constituição da República. Em face das variadas inspirações presentes no direito privado, somente o texto constitucional estaria apto a fornecer a necessária unidade do sistema. Isso porque, particularmente entre nós, princípios como o da dignidade da pessoa humana ganham inegável projeção e se renovam a partir da Constituição da República de 1988, e, assim, assumem a condição de norte interpretativo da totalidade das normas de caráter civilístico.

Um dos principais expoentes da escola do direito civil constitucional revela-se na figura do professor da Universidade de Camerino, PIETRO PERLINGIERI. Sobre o presente tema, assim se manifesta o autor italiano:

\begin{abstract}
A questão da aplicabilidade simultânea de leis inspiradas em valores diversos resolve-se somente tendo consciência de que o ordenamento jurídico é unitário. A solução para cada controvérsia não pode ser mais encontrada levando em conta simplesmente o artigo de lei que parece contê-la e resolvê-la, mas, antes à luz do inteiro ordenamento jurídico, e, em particular, de seus princípios fundamentais, considerados opções de base que o caracterizam (PERLINGIERI, 1997: p. 5).
\end{abstract}

Em verdade, a mencionada linha teórica assenta-se na impossibilidade de o Código Civil centralizar o sistema jurídico, o que abriria espaço para a adoção do texto constitucional como núcleo apto a lhe dar a pretendida coerência. A principiologia emanada das normas constitucionais teria por função a unificação do sistema, diante de um quadro legislativo notadamente variado. Por isso, apoiando-se em princípios como o da dignidade da pessoa humana, demonstrar-se-ia necessário encontrar novos desenhos para velhos institutos, possibilitando soluções que propugnem pela verdadeira justiçaii. 
Observa-se, pois, uma busca pela coerência sistemática, diante de variadas inspirações a permearem os elementos do direito civil.

Assim, uma das premissas em que se assenta a aludida linha doutrinária é a de que o Código Civil não mais ocupa o papel central no âmbito do direito privado. A impossibilidade de tratar variadas matérias em um único texto legal leva ao surgimento de vasta legislação ordinária, que tende a abordar, de maneira setorizada, diversos temas de direito civil.

Essa ocorrência é também conhecida pela expressão descodificação do direito civiliii. Em consonância com tal inteligência, não haveria mais considerar o Código Civil como a Constituição do direito privado, principalmente em razão da ausência de completitude do seu texto. Por isso, hoje, convivendo com outros instrumentos legais, o Código Civil não mais exerceria seu anterior papel unificador do sistema jurídico privatístico.

É dizer, o centro do sistema não mais se revela no Código Civil. Há, em verdade, uma variada gama de matérias que são tratadas isoladamente, perfilhando pequenas esferas jurídicas, também chamadas de microssistemas. Essa temática foi desenvolvida por NATALINO IRTI, que assim se manifesta:

Um sistema, que já não corresponda a um corpo definido de leis, assume um novo valor. Não mais monossistema, ligado às estruturas do Código Civil, desenvolvido de acordo com o desenho e a divisão deste; mas polissisistema, como um quadro de princípios, no qual se insere uma pluralidade de microssistemas e de lógicas setoriais. $\mathrm{O}$ Código Civil é apenas uma parte do sistema de direito privado, que tem no centro a Constituição, da qual são irradiados feixes de núcleos legislativos (IRTI, 1979: p. 145) ${ }^{\text {iv }}$

O sistema, então, encontra-se dividido em variados compartimentos, que procuram tratar de temas específicos. Há uma multiplicidade de microssistemas. A título de exemplo, no Brasil, existem diplomas específicos que tratam de matérias setorizadas, como o Código de Defesa do Consumidor, o Estatuto da Criança e do Adolescente ou a Lei do Inquilinato. Tais matérias possuem nítido conteúdo civil, mas não se encontram albergadas no corpo de um único texto legal.

Trata-se de um fenômeno verificado em diversas ordens jurídicas de origem romano-germânica. O principal fator de propagação desses diplomas legais apartados encontra-se na necessária linguagem setorial no trato de alguns temas. $\mathrm{O}$ direito privado é permeado por diversas matérias dotadas de complexidade ímpar. Seria impossível condensar todo conteúdo em um único instrumento legislativo. Assim, diversas leis ordinárias vêm dar delineamentos específicos e setorizados a campos em que não se prescinde da utilização de uma linguagem especial, nem sempre dotada de conteúdo essencialmente jurídico. Esse caminho ao polissistema legislativo é o que demarca o advento da chamada "era dos estatutos" (FACCHINI NETO, 2006: p. 25).

A coerência e uniformidade do sistema jurídico privatístico deslocam de eixo, ao argumento de que diante de variados diplomas legislativos tais características se estruturam em razão do texto constitucional. Somente a Constituição tem a capacidade de integrar o sistema, em razão do conteúdo e da principiologia que carrega. Dessa maneira, a interpretação e a aplicação do direito privado deslocam-se do Código Civil pretendendo encontrar uniformidade no texto constitucional.

Outro ponto em que se assenta a constitucionalização do direito civil é o fim da dicotomia entre público e privado. Na atualidade, não há mais considerar direito público e direito privado como esferas estanques e distintas. Essa realidade, típica do século 
XVIII ${ }^{v}$, não mais prospera, não sendo possível imaginar um ordenamento no qual não haja um intercâmbio entre os referidos campos.

O Estado passa a intervir na atividade privada por meio de políticas que, ocasionalmente, visando a bons propósitos, acabam mesmo por limitar excessivamente a liberdade e a autonomia privada. Em paralelo, o texto constitucional passa a tratar de temas típicos de direito civil, levando antigos institutos a novos desenhos. Assim, temas como casamento, adoção, contratos ou propriedade passam a ser objeto de normas de caráter essencialmente público.

O direito público, por sua vez, também não se isenta de uma maior influência por parte do direito privado. A Administração Pública passa a estar adstrita a normas de conteúdo civil, uma vez que atua como particular em determinadas situações. Assim, matérias como contratos, propriedade ou responsabilidade civil são ampliadas para que tenham aplicação garantida em relação a tais situações. Nesse sentido, discorre MICHELE GIORGIANNI (1998: p. 54):

\begin{abstract}
A aproximação entre as duas esferas já está madura (...) também pela íntima evolução que se está operando no próprio âmbito do Direito Administrativo. Também aqui - seja concedido ao privatista notá-lo com alguma satisfação, fala-se em crise ou até mesmo de <<caos〉> por causa da penetração dos elementos privatistas. Na verdade, já existe uma larga zona em que o Direito Administrativo se comporta exclusivamente como um direito estatutário dos entes públicos, do qual deriva uma ampla comunhão de conceitos e de princípios com a correspondente disciplina dos entes privados.
\end{abstract}

Desse modo, pode-se, hoje, inegavelmente, falar da quebra desse paradigma de separação absoluta entre público e privado. Não há mais sentido prático na manutenção da dicotomia, excetuando-se razões primordialmente didáticas.

Nesse contexto, a referida quebra potencializa a defesa, pelos seus adeptos, da constitucionalização do direito civil. Não mais havendo empecilhos dogmáticos, o intérprete deve buscar soluções práticas, tendo sempre como base os valores fundamentais inseridos na Constituição.

Para tanto, porém, parte-se da aceitação da ideia de que os preceitos constitucionais que elencam matérias de direito civil teriam aplicabilidade direta, prescindindo de qualquer tratativa por parte da legislação ordinária. A Constituição, portanto, estabeleceria diretamente normas de conduta no âmbito privado. Diante desse panorama, assim se manifesta PERLINGIERI acerca da aplicação direta do texto constitucional sem intermediação de instrumentos legais ordinários:

Não existem argumentos que contrastem a aplicação direta: a norma constitucional pode, também sozinha (quando não existirem normas ordinárias que disciplinem a fattispecie em consideração), ser a fonte da disciplina de uma relação jurídica de direito civil. Esta é a única solução possível, se se reconhece a preeminência das normas constitucionais - e dos valores por ela expressos - em um ordenamento unitário, caracterizado por tais conteúdos. (PERLINGIERI, 1997: p. 11)

Essas teorizações ligadas ao que se convencionou chamar direito civil constitucional encontraram no Brasil terreno fértil para novos desenvolvimentos. Quando das primeiras tratativas acerca da mencionada construção doutrinária, estava em vigência o antigo Código Civil, datado de 1916. Tal diploma, porém, tinha suas 
raízes no século XIX e, por isso, refletindo uma estrutura social diferente, se mostrava incompatível com os anseios de valorização do conteúdo humano. Sua inspiração notadamente liberal desdobrava-se em uma exacerbada valorização de um pensamento patrimonialista.

Nesse contexto, assim se expressou TEPEDINO acerca da desatualização do Código Civil:

O Código Civil, bem se sabe, é fruto das doutrinas individualista e voluntarista que, consagradas no Código de Napoleão e incorporadas pelas codificações do século XIX, inspiraram o legislador brasileiro quando, na virada do século, redigiu nosso Código Civil de 1916. Àquela altura, o valor fundamental era o indivíduo. O direito privado tratava de regular, do ponto de vista formal, a atuação dos sujeitos de direito, notadamente o contratante e o proprietário, os quais, por sua vez, a nada aspiravam senão ao aniquilamento de todos os privilégios feudais: poder contratar, fazer circular as riquezas, adquirir bens como expansão da própria inteligência e personalidade, sem restrições ou entraves legais. Eis aí a filosofia do século XIX, que marcou a elaboração do tecido normativo consubstanciado no Código Civil (TEPEDINO, 1999: p. 2).

Com o advento do Novo Código Civil, em 2002, novas abordagens foram efetivadas. Diante de uma codificação que tem como base o uso de conceitos jurídicos indeterminados e de cláusulas gerais, buscou-se no texto constitucional um vetor interpretativo para a sua aplicação. O caráter aberto do sistema possibilitou que seu preenchimento se desse com a utilização de princípios de ordem constitucional. Assim, expressões como função social ou boa-fé passam, em razão do desconhecimento de seu verdadeiro conteúdo, a buscar algum norte interpretativo na Constituição.

A escola do direito civil constitucional se atualizou, portanto, e permitiu um contínuo fluxo de construções doutrinárias. Apregoa-se, ainda hoje, a necessária releitura do direito privado à luz da Constituição, encontrando, assim, seus institutos uma correta aplicação no sistema.

\section{Por uma abordagem crítica da constitucionalização do direito civil}

Como antes afirmado, revela-se imperioso que o conteúdo apresentado seja analisado sob um viés crítico. A escola do direito civil constitucional teve importância ímpar no desenvolvimento de variados estudos e construções doutrinárias. Importa, todavia, verificar a validade de suas premissas e, ainda, se a aplicação e incremento de suas propostas encontram espaço hodiernamente.

Um primeiro ponto a ser abordado é o da existência dos chamados microssistemas e, consequentemente, o da busca da unidade sistemática da ordem jurídica no texto constitucional. A existência de inúmeros instrumentos legislativos especiais nos mais diversos campos do direito privado retirou, sobremaneira, a importância que detinha o Código Civil e, na linha do que se veio de expor, levou a um repensar do sistema a partir do texto constitucional, aparentemente o único apto a fornecer a necessária unidade.

Ocorre que, na verdade, importa perceber que, na maioria das vezes, se está diante apenas da verificação da conformidade da lei com a Constituição. Esse variado leque de legislação extravagante deve ser, pois, controlado à luz da Constituição, de modo a se verificar sua adequabilidade em relação aos preceitos e valores 
constitucionais. Por isso, instrumentos de controle de constitucionalidade devem ter especial relevo.

Passo contínuo, apresenta-se também importante identificar a exata extensão e importância do elemento hermenêutico. Isso porque a interpretação das normas ordinárias, bem como dos institutos por ela desenhados, deve ser realizada em conformidade com a Constituição. Esse labor revela-se extremamente relevante e traz consigo a preocupação de acatamento à axiologia emanada do texto constitucional. Assim, diante dos valores inseridos nas normas constitucionais, com a carga simbólica, política e jurídica que revelam, é imperativo que a legislação infraconstitucional também os siga, tanto na sua elaboração, quanto na interpretação e aplicação.

Vê-se, assim, que não se está diante de nenhuma técnica nova. Trata-se apenas de buscar os pressupostos de validade que o sistema impõe. Diante do necessário primado da Constituição, nada mais natural que verificar a conformidade de todo o sistema jurídico com os contornos definidos constitucionalmente. É dizer, se uma norma qualquer não está em consonância com a Constituição, ela deve, pois, ser extirpada do ordenamento jurídico, em razão, simplesmente, da ausência do seu pressuposto de validade. Assim, como assevera VILLELA, a expressão "direito civil constitucional é, no mínimo, redundante" (VILLELA, 2010), em razão de toda norma de direito civil dever obediência ao texto constitucional.

Distinta, porém, é a questão da chamada superação da dicotomia entre direito público e direito privado. Como se teve oportunidade de falar, o aludido fenômeno serve como justificativa comum para um recurso direto, não raramente descuidado, à Constituição, objetivando solucionar problemas típicos de direito privado. Muitas vezes essa compreensão leva a equívocos, conforme demonstra MOTA PINTO (2005: p. 43):

Há, porém, equívocos importantes a desfazer. Assiste-se hoje, sem dúvida, à superação de certos pressupostos ideológicos do passado, do modelo liberal da justiça, da absoluta separação Estado/Sociedade, do Estado abstencionista e dos princípios da liberdade e igualdade encarados de um ponto de vista meramente formal [...]. Mas daí não decorre necessariamente uma adesão às teses da <constitucionalização do direito civil>, da <publicização do direito privado> e muito menos da superação da distinção entre o direito público e o direito privado. Sem prejuízo, contudo, do papel da Constituição como Lei fundamental e, nessa medida, do controlo de constitucionalidade das leis civis (leis ordinárias), assim como sem prejuízo do reconhecimento dos princípios constitucionais no preenchimento das cláusulas gerais e conceitos indeterminados de direito civil, do princípio da interpretação em conformidade com a Constituição, etc.

É, por isso, importante destacar que os novos pressupostos ideológicos não justificam uma superação definitiva da divisão entre direito público e direito privado. Pode-se constatar a existência de pontos convergentes entre os dois grandes campos, mas não a extinção de uma separação de importância sistemática. A aproximação de institutos e conceitos de direito público e de direito privado não afasta, por si só, a importância de se manter a referida classificação ${ }^{\mathrm{vi}}$.

O exercício de qualificação de uma relação jurídica como de direito público ou de direito privado mantém-se como de extrema relevância para a verificação das normas a serem aplicadas, uma vez que os regimes jurídicos são diversos. Para que se possa aplicar a um caso concreto a correlata norma, demonstra-se imprescindível a identificação do regime em que está inserida a relação jurídica. Só por meio desse 
exercício é possível constatar as eventuais peculiaridades existentes, fato que, por si, fornece embasamento suficiente para a manutenção dessa categorização sistemática.

Ademais, outro questionamento que se apresenta reside na questão da aplicabilidade direta das normas constitucionais, sem o necessário auxílio de lei ordinária. Como visto, para a escola do direito civil constitucional, a tarefa do jurista não se restringe à verificação da constitucionalidade - conformidade e proporcionalidade - de determinada legislação, nem tampouco a um labor hermenêutico. Por suas construções teóricas, é possível pensar a aplicabilidade direta das normas constitucionais, sem qualquer intermediação por leis ordinárias.

Transpondo o debate para nossa realidade mais recente, a Emenda Constitucional $\mathrm{n}^{\circ}$ 66, de 13 de julho de 2010, vem suscitando alguma polêmica centrada na sua aplicabilidade direta, fazendo com que, direta ou indiretamente, sejam sopesados argumentos que se prendem à escola do direito civil constitucional.

Isso porque, antes da promulgação da referida Emenda, o $\S 6^{\circ}$ do art. 226 da Constituição da República dispunha: "o casamento civil pode ser dissolvido pelo divórcio, após prévia separação judicial por mais de um ano nos casos expressos em lei, ou comprovada separação de fato por mais de dois anos". O novo texto, entretanto, suprimiu uma parte desse dispositivo constitucional, que passou a ter a seguinte redação: "o casamento civil pode ser dissolvido pelo divórcio".

Parte da doutrina e da jurisprudência rapidamente entendeu estar-se diante de norma como que de eficácia plena ${ }^{\text {vii }}$, a prescindir de qualquer regulamentação por lei ordinária. Tendo por base, aparentemente, a proposta do direito civil constitucional, firmou-se entendimento de que a intermediação legislativa ordinária não se demonstraria necessária, principalmente sob o argumento, utilizado um tanto quanto superficialmente, de que se estaria diante de valores e opções que visam à dignidade da pessoa humana.

Ocorre que esse entendimento, já possuidor de relevante aceitação na prática jurídica, não se coaduna com o que se deve esperar de um ordenamento jurídico sistematizado. A reforma apenas deixou de impor, com força constitucional, determinados requisitos para a realização do divórcio, restando ao legislador ordinário, justamente por se dever observar o devido processo legislativo, espaço para regulamentar a questão da maneira que melhor lhe aprouvesse. Nesse sentido, assevera VILLELA (2010):

A emenda Constitucional não declarou seu repúdio aos requisitos que constavam do $\S 6^{\circ}$ do Art. 226. Não os proscreveu do direito brasileiro. Onde está escrito que ela o tenha feito? Apenas dispensou (na medida em que não os repetiu), o que é algo bem diferente. Uma vez que apenas os dispensou, o legislador ordinário fica livre para conservá-los ou não. E se os conservar hoje, poderá mandá-los para o lixo amanhã. Voltar a adotá-los em futuro próximo ou remoto. E assim por diante. Tudo segundo seu próprio, livre e amplo juízo de conveniência.

Admitir tal repúdio, que não se demonstra expressamente, acaba por afastar um necessário labor do Poder Legislativo e, assim, em nome de uma propalada defesa da dignidade da pessoa humana, colocar em risco valores democráticos, igualmente essenciais. A Constituição prevê a necessidade de elaboração de leis e estabelece, para tanto, rigorosamente, o funcionamento do processo legislativo. É necessário, portanto, que se preste tributo à segurança jurídica, elemento base para que se construa um ordenamento que se pretenda justo. 
O fenômeno, porque jurídico, é complexo. A nova codificação, ainda que, como a anterior, possuidora de antigas raízes, carreou, de fato, novos valores e uma nova estrutura. Importa, pois, verificar a necessidade de se recorrer à Constituição para suprir valores eventualmente não processados pelo direito civil. Nessa contenda, assim se manifesta VILLELA (2010):

Quando valores novos que, por natureza, devam ser processados no direito civil ganham primeiro o tecido constitucional, justifica-se que sejam aplicados diretamente até que sejam incorporados à legislação ordinária. Foi o caso, por exemplo, dos direitos da privacidade, da intimidade, da recusa ao tratamento médico e outros similares, que começaram pela Constituição e só depois chegaram ao Código Civil. É uma situação absolutamente transitória e denota, possivelmente, o único sentido em que a expressão direito civil constitucional merece curso, apesar da manifesta impropriedade dos termos.

O novo Código Civil trouxe consigo valores que antes estavam restritos ao texto constitucional. Eles, porém, não se substituem reciprocamente, tampouco se confrontam: antes, se complementam. Não há porque realizar um recurso assistemático, superficial e, pior, arbitrário à Constituição. O direito civil constitucional, entendido como aplicação direta da Constituição, só se justifica quando da eventual ausência de legislação ordinária suficientemente regulamentadora. A partir do momento que o Código Civil aborda novos temas, conferindo a seus institutos contornos em conformidade com o texto constitucional, esvazia-se uma das premissas em que se assenta a constitucionalização do direito civil.

\section{CONCLUSÃO}

Embora a Constituição não possa, por si só, realizar nada, ela pode impor tarefas. A Constituição transforma-se em força ativa se essas tarefas forem efetivamente realizadas, se existir a disposição de orientar a própria conduta segundo a ordem nela estabelecida, se, a despeito de todos os questionamentos e reservas provenientes dos juízos de conveniência, se puder identificar a vontade de concretizar essa ordem. Concluindo, pode-se afirmar que a Constituição converter-se-á em força ativa se fizerem-se presentes, na consciência geral - particularmente, na consciência dos principais responsáveis pela ordem constitucional -, não só a vontade de poder (Wille zur Macht), mas também a vontade de Constituição (Wille zur Verfassung). (Grifos no original) (HESSE, 1991: p. 19)

Transformar a Constituição em força ativa e orientar as normas jurídicas e os comportamentos individuais e coletivos de acordo com as opções constitucionais são exigências do pensamento jurídico contemporâneo que resultam em grandes avanços. Como decorrência direta tem-se, por exemplo, a naturalidade com a qual hoje se reconhece a força normativa dos preceitos constitucionais.

A crítica aqui realizada deve ser entendida como tentativa de contribuição aos desenvolvimentos teóricos e jurisprudenciais futuros, inclusive ao fenômeno - se bem compreendido - conhecido por neoconstitucionalismo(s), que, de resto, não se confunde com as ponderações acima rebatidas. 
O foco das futuras discussões, em que pese os avanços já verificados, deve voltar-se à importância do direito privado na efetivação dos direitos fundamentais. Assim, compreender-se-á melhor a dimensão humana desse campo do sistema jurídico, muitas vezes desprezada pela crítica de um excessivo patrimonialismo. Ademais, esse retorno possibilitará a retomada de debates concernentes à autonomia política do povo e à autonomia privada do cidadão.

Isso porque os efeitos práticos decorrentes do direito civil constitucional no espaço jurídico brasileiro podem ser terrificantes, a começar pelo eventual desprezo à legislação infraconstitucional.

Sob o argumento de que o sistema majoritário não corresponde às demandas por legitimidade democrática, ignora-se a existência legítima de regulamentação infraconstitucional ao argumento de se priorizar, por meio de suposta ponderação, a efetividade de comandos constitucionais. Entretanto, não se respeita qualquer regra de discurso, qualquer ônus argumentativo.

Não cabe, aqui, discorrer sobre a falta de responsividade dos sistemas majoritários, especialmente diante da verificação de que eles nem sempre corresponderam às demandas sociais. Contudo, inaceitável admitir-se, a partir da premissa de que esse modelo de participação democrática é falho, o seu puro e simples desprezo, seguido do protagonismo dos pretensos guardiães da democracia. Parece, mesmo, evidente: o desprezo à lei, ao seu extremo, é desprezo à própria democracia.

Há um tênue limite entre a concretização da vontade da Constituição e o desprezo à autodeterminação legislativa. Desse último, pode-se extrair, ainda, grave constatação, pois a desconsideração da manifestação do legislador democrático ilustra seu descrédito e induz à crença na sua incapacidade para instrumentalizar a efetivação dos preceitos constitucionais.

A valoração das opções constitucionalmente relevantes à sociedade brasileira deve ser realizada também pelo Legislativo. Nesse contexto, torna-se imprescindível a real discussão e implementação de uma reforma política efetiva, centrada, por exemplo, nas noções de accountability, responsability e responsiviness, paralelamente à igualmente necessária conscientização do dever de autocontenção por parte do Judiciário.

Some-se a isso o fato de se presenciar o empobrecimento dos estudos de direito civil, em razão das construções doutrinárias serem comumente elaboradas tomando por base o texto constitucional. Essa preocupação exacerbada leva, muitas vezes, a um tratamento desmazelado de temas típicos de direito civil. Não se vê uma busca pelo aprimoramento dos institutos e conceitos, mas sim uma tentativa de justificá-los com a aplicação direta da Constituição.

Como consequência, toda a discussão se torna superficial. Em razão da falta de profundidade das análises realizadas, perde-se a noção do real significado dos institutos de direito privado, também constitucionalmente relevantes.

Esse fenômeno deve ser enfrentado, pois os prejuízos decorrentes da diluição semântica desses institutos e princípios são prejudiciais.

Diante do Novo Código Civil, deve o intérprete conciliar aquela vontade de Constituição, o imperativo de efetividade dos preceitos constitucionais e a defesa dos direitos fundamentais com o igualmente essencial respeito à legislação infraconstitucional, à autodeterminação política perpetrada pelo legislador democrático e aos valores e institutos de direito privado. Essa possibilidade é aberta, como já se disse, pelas cláusulas gerais e pelo preenchimento dos conceitos indeterminados, em uma atividade constitucionalmente conforme. 
Houve avanços, como se viu, porém é tempo de refletir sobre os caminhos trilhados e os desvios cometidos. Tal é a condição para se dar o próximo passo, rumo a um diálogo leal entre Constituição e direito privado.

\section{REFERÊNCIAS}

BONAVIDES, Paulo. Curso de Direito Constitucional. 7. ed. São Paulo: Malheiros, 1997.

CANARIS, Claus-Wilhelm. Direitos Fundamentais e Direito Privado. Trad. Ingo Wolfgang Sarlet e Paulo Mota Pinto. Coimbra: Almedina, 2003.

FACCHINI NETO, Eugênio. Reflexões histórico-evolutivas sobre a constitucionalização do direito privado. In: SARLET, Ingo Wolfgang (Org). Constituição, Direitos Fundamentais e Direito Privado. 2. ed. rev. e ampl., Porto Alegre: Livraria do Advogado, 2006.

GIORGIANNI, Michele. O Direito Privado e suas atuais fronteiras. Revista dos Tribunais, São Paulo, ano 87, nº 747, janeiro, 1998.

HESSE, Konrad. A Força Normativa da Constituição. Trad. Gilmar Ferreira Mendes. Porto Alegre: Sergio Antonio Fabris Editor, 1991.

IRTI, Natalino. Leggi speciali (dal mono-sistema al poli-sistema). Rivista di Diritto Civile, Padova, ano XXV, parte I, 1979.

MARTINS-COSTA, Judith. O direito privado como um 'sistema em construção': as cláusulas gerais no Projeto de Código Civil Brasileiro. Revista de Informação Legislativa, Brasília, ano 35, n. 139, julho-setembro, 1998.

MARTINS-COSTA, Judith. Os Direitos Fundamentais e a opção culturalista do Novo Código Civil. In: SARLET, Ingo Wolfgang (Org). Constituição, Direitos Fundamentais e Direito Privado. 2. ed. rev. e ampl., Porto Alegre: Livraria do Advogado, 2006.

MOTA PINTO, Carlos Alberto da. Teoria Geral do Direito Civil. 4. ed. Atualizada por António Pinto Monteiro e Paulo Mota Pinto. Coimbra: Coimbra Editora, 2005.

MOTA PINTO, Paulo. Autonomia privada e discriminação: algumas notas. In: SARLET, Ingo Wolfgang (Org). Constituição, Direitos Fundamentais e Direito Privado. 2. ed. rev. e ampl., Porto Alegre: Livraria do Advogado, 2006.

PERLINGIERI, Pietro. Perfis do Direito Civil. Trad. Maria Cristina De Cicco. $3^{\text {a }}$ ed., Rio de Janeiro: Renovar, 1997.

SILVA, José Afonso da. Aplicabilidade das Normas Constitucionais. 7. ed., Malheiros: São Paulo, 2007.

SIQUEIRA JÚNIOR, Paulo Hamilton. A dignidade da pessoa humana no contexto da pós-modernidade. In: MIRANDA, Jorge. SILVA, Marco Antônio Marques (Coord). Tratado Luso-Brasileiro da Dignidade Humana. São Paulo: Quartier Latin, 2008.

TEPEDINO, Gustavo. Premissas Metodológicas para a Constitucionalização do Direito Civil. In: TEPEDINO, Gustavo. Temas de Direito Civil. Rio de Janeiro: Renovar, 1999.

VILLELA, João Baptista. Entrevista: Emenda Constitucional $\mathrm{n}^{\mathrm{o}} 66$ - Outras Impressões. Carta Forense, ano VI, São Paulo, Disponível em: http://www.cartaforense.com.br/Imprimir.aspx?id=6075. Acesso em: 19.11.2011.

VIEIRA DE ANDRADE, José Carlos. Os Direitos Fundamentais na Constituição Portuguesa de 1976. Reimpressão. Coimbra: Almedina, 1987.

i TEPEDINO assevera que o direito civil exercia outro papel, dentro da perspectiva do estado liberal. Segundo o autor: "Ao direito civil cumpriria garantir à atividade privada, e em particular ao sujeito de direito, a estabilidade proporcionada por regras quase imutáveis nas suas relações econômicas. Os 
chamados riscos do negócio, advindos do sucesso ou do insucesso das transações expressariam a maior ou menor inteligência, a maior ou menor capacidade de cada indivíduo. (TEPEDINO, 1999: p. 3)

ii Nas palavras de TEPEDINO: "Se o Código Civil mostra-se incapaz - até mesmo por sua posição hierárquica - de informar, com princípios estáveis, as regras contidas nos diversos estatutos, não parece haver dúvida que o texto constitucional poderá fazê-lo, já que o constituinte, deliberadamente, através de princípios e normas, interveio nas relações de direito privado, determinando, conseguintemente, os critérios interpretativos de cada uma das leis especiais. Recupera-se, assim, o universo desfeito, reunificando-se o sistema". (TEPEDINO, 1999: p. 13)

iii Nesse sentido, aduz PERLINGIERI: "O Código Civil certamente perdeu a centralidade de outrora. O papel unificador do sistema, tanto nos seus aspectos mais tradicionalmente civilísticos quanto naqueles de relevância publicística, é desempenhado de maneira cada vez mais incisiva pelo Texto Constitucional. Falar em descodificação relativamente ao Código vigente não implica absolutamente a perda do fundamento unitário do ordenamento, de modo a propor a sua fragmentação em diversos microordenamentos e em diversos microssistemas, com ausência de um desenho global". (PERLINGIERI, 1997: p. 6)

iv Tradução livre do original: "Un sistema, che ormai non combacia con un corpo definito di leggi, assume un nuovo valore. Non piú mono-sistema, correlativo alle strutture del codice civile, svolto secondo il disegno e le partizioni di esso; ma poli-sistema, come quadro d'insieme, o cornice di principi, in cui si iscrive una pluralità di micro-sistemi e di logiche di settore. Il codice civile è soltanto una parte del sistema del diritto privato, che vede al centro la Costituzione e di qui irradiarsi un fascio di nuclei legislativi”. (IRTI, Natalino, 1979: p. 145)

v FACCHINI NETO aduz que é nesse contexto histórico que se encontra a mais intensa divisão dicotômica entre público e privado. Assevera o autor que: "o Direito Público passa a ser visto como o ramo do direito que disciplina o Estado, sua estrutura e funcionamento, ao passo que o Direito Privado é compreendido como o ramo do direito que disciplina a Sociedade civil, as relações intersubjetivas, e o mundo econômico (sob o signo da liberdade)". (FACCHINI NETO, 2006: p. 19)

vi Nesse ponto, é imperioso, novamente, transcrever as palavras de MOTA PINTO: "Dir-se-á, numa breve síntese conclusiva, que a distinção entre o direito público e o direito privado é uma tarefa de classificação e arrumação sistemática e, nessa medida, uma tarefa da ciência do direito, que deve ser despida de conotações ideológicas e não põe em causa o postulado fundamental da unidade da ordem jurídica". (MOTA PINTO, 2005: p. 44)

vii Importa salientar que a referida classificação é realizada de acordo com clássica obra do professor José Afonso da Silva, não estando adstrita a eventuais discussões acerca da manutenção de sua teoria. Ver: SILVA, José Afonso da. Aplicabilidade das Normas Constitucionais. 7ª ed., Malheiros: São Paulo, 2007. 